\title{
Análise das sete dimensões da gestão do conhecimento em uma indústria do setor metal-mecânico
}

\author{
Analysis of seven dimensions knowledge management in an industry sector the \\ metal-mechanic.
}

\author{
Isabella Tamine Parra Miranda ${ }^{32}$ \\ Luiz Alberto Pilatti ${ }^{33}$
}

Artigo recebido para publicação em Out./2013 e aceito para publicação em Maio/2014.

\section{RESUMO}

Este estudo tem por objetivo identificar práticas vinculadas a GC na indústria pesquisada conforme classificação proposta por Terra (2001). Trata-se de um estudo exploratório em uma indústria do setor metal-mecânico, no norte do Paraná. Para a coleta de dados foi utilizada uma escala social desenvolvida por Terra (2001). Evidenciou-se que a organização estudada classifica-se diante das práticas de GC como empresa que aprende. Os resultados da pesquisa apresentam concordância para cada prática de gestão registrada na organização. Concluiu-se que a organização está alinhada às sete dimensões da Gestão do Conhecimento, propostas por Terra (2001) e, portanto, dá condições propícias ao compartilhamento e à criação de conhecimento.

Palavras-chave: Conhecimento. Práticas de Gestão do Conhecimento. Aprendizagem organizacional.

\begin{abstract}
This study aims to identify practices associated GC in specific industry as classified by Terra (2001). This is an exploraty study of the industry in a metal-mechanic sector in north Paraná. For data collection we used a scale developed by Terra (2001). It was evident that the organization studied ranks before the GC practices as a company that learns. The survey results show concordance for each management practice in the organization registered. It was concluded that the organization is aligned to the seven dimensions of knowledge management, proposed by Terra (2001), and therefore gives conditions for the creation and sharing of knowledge.
\end{abstract}

Keywords: knowledge. Practices Knowledge Management. Organizational Learning.

32 Aluna do Programa de Pós-Graduação em Engenharia de Produção (PPGEP), do câmpus Ponta Grossa da Universidade Tecnológica Federal do Paraná (UTFPR). Professora efetiva na Fundação Faculdade de Filosofia, Ciências e Letras de Mandaguari (FAFIMAN-UNIMAN). Email: isabellamiranda@fafiman.br.

33 Doutor em Educação Física pela Universidade Estadual de Campinas (UNICAMP). Professor do Programa de Pós-Graduação em Engenharia de Produção (PPGEP), do câmpus Ponta Grossa da Universidade Tecnológica Federal do Paraná (UTFPR). Bolsista de Produtividade em Pesquisa do CNPq. E-mail: lapilatti@utfpr.edu.br. 


\section{INTRODUÇÃO}

Atualmente, a sociedade caracteriza-se como a sociedade do conhecimento, onde os ativos intangíveis, caracterizados como o capital humano e capital estrutural interno e externo, são considerados como responsáveis pela riqueza produzida nas organizações (PILATTI; BEJARANO, 2005). A concretização dos objetivos e das estratégias organizacionais depende significativamente das pessoas. $O$ capital humano agrega trabalho, inteligência, conhecimento e aprendizado constante à organização, gerando inovação e competitividade.

A competitividade faz parte do mundo empresarial, exigindo que as organizações valorizem o conhecimento, utilizando-o, compartilhando-o e tomando-o como importante ferramenta para a sua própria sustentabilidade.

Para Nonaka e Takeuchi (1997), o sucesso das empresas se deve às suas competências em criar conhecimento organizacional, disseminá-lo por toda organização e incorporá-lo a produtos, serviços e sistemas.

$\mathrm{Na}$ literatura disponível sobre gestão do conhecimento encontram-se diversos modelos, sendo a maior parte desses focado em processos (DAVENPORT; 1994; GARVIN, 1995; LEHTIMAKI, 1991; OSTROFF; SMITH, 1992), visto que os processos são considerados facilitadores no desenvolvimento das práticas gerenciais.

As práticas gerenciais devem ser coordenadas sistemicamente nos planos operacional e estratégico, através de normas informais e formais. Esses pontos devem estar alinhados com as ações que são indispensáveis ao processo de inovação. Esse processo necessita combinar diferentes conhecimentos, habilidades, tecnologias e conhecimento de diversos setores (TERRA, 2001).

A gestão do conhecimento, na visão de Terra (2001), está ligada à capacidade de utilização e combinação pela organização das fontes e tipos de conhecimento, responsáveis pelo desenvolvimento de competências específicas e capacidade de inovação, sendo necessário à adoção de vários planos e dimensões da prática gerencial relacionada à gestão do conhecimento.

Cada vez mais as organizações estão considerando a criação de conhecimento como fator de competitividade. Porém, isto não basta para o sucesso. 
É necessário que as organizações realmente disseminem e promovam a criação de conhecimento. É importante que exista um processo sistematizado e consciente para que a criação de conhecimento possa ser efetiva e gere resultados positivos. Reconhecida a importância da criação do conhecimento organizacional é necessário que este conhecimento seja compartilhado para que se gerem novos produtos, processos e serviços.

Nesse cenário, esse estudo tem por objetivo identificar práticas vinculadas a GC na indústria pesquisada conforme classificação proposta por Terra (2001).

\section{AS SETE DIMENSÕES DO CONHECIMENTO}

Terra (2001) identifica sete dimensões da gestão do conhecimento, centrais na gestão das organizações para a criação de condições propícias ao compartilhamento e criação do conhecimento. A Figura 1 apresenta as dimensões identificadas pelo autor:

Figura 1: Gestão do conhecimento: planos e dimensões.

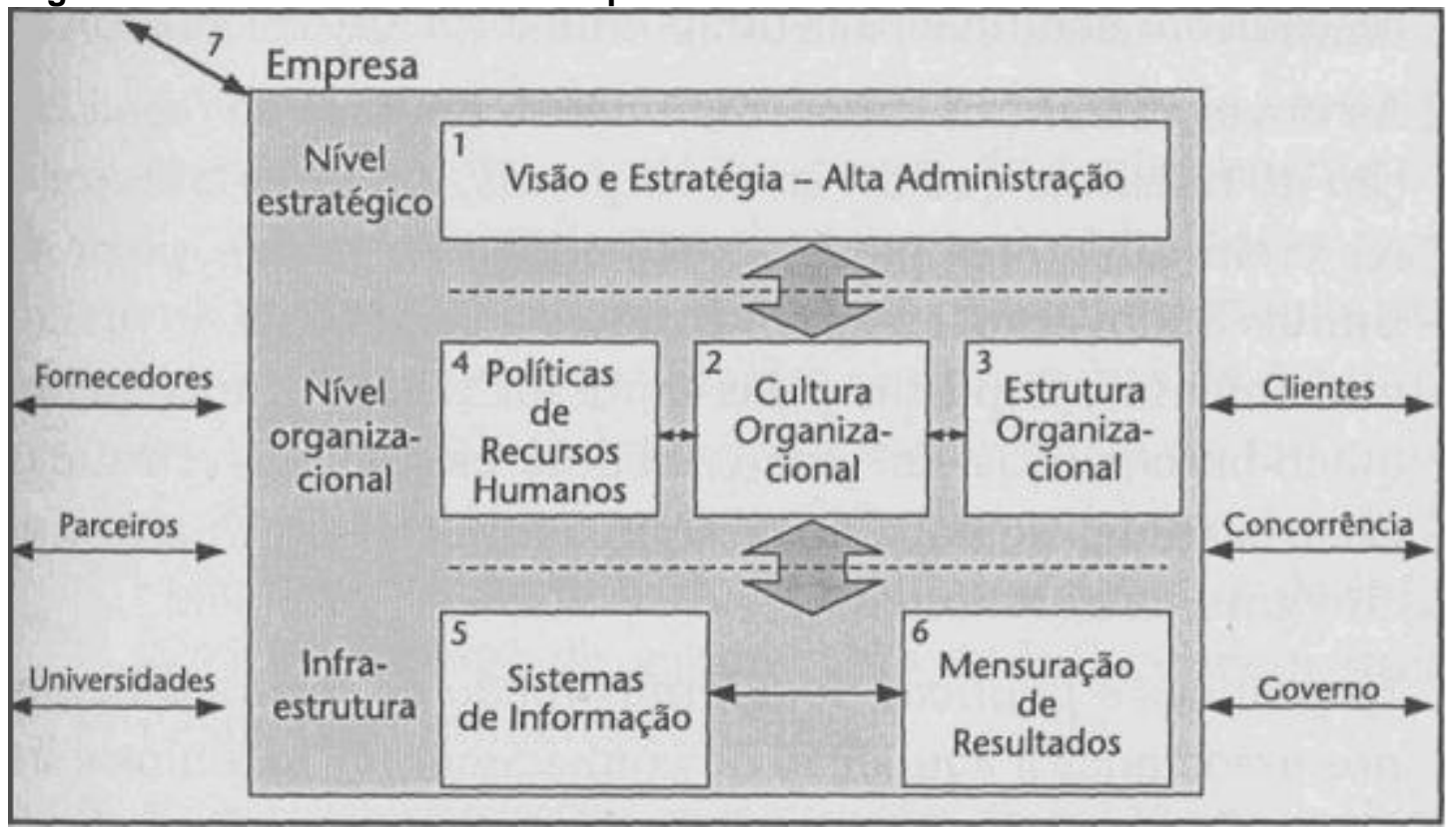

Fonte: Terra (2001, p. 83).

A Dimensão 1 - Fatores estratégicos e o papel da alta administração. Essa dimensão é indispensável na clarificação da estratégia empresarial e na definição de metas. O papel da alta administração apresenta um caráter de ação, de alavancagem de habilidades e incentivos para enfrentar riscos (TERRA, 2001). 
Em relação à Dimensão 2 - Cultura e valores organizacionais, a organização deve desenvolver uma cultura voltada à inovação, experimentação, aprendizado contínuo, comprometida com resultados de longo prazo e com a otimização de todas as áreas da empresa. Terra (2001) afirma que a missão e os valores da organização devem ser amplamente conhecidos e incorporados e deve existir um elevado sentimento de confiança entre a organização e seus colaboradores.

Dimensão 3 - Estrutura organizacional. A estrutura organizacional deve relacionar-se ao trabalho de equipes multidisciplinares com alto grau de autonomia. Terra (2001) propõe que a estrutura organizacional deve implementar um modelo flexível de gestão.

Dimensão 4 - Administração de recursos humanos. Essa dimensão tem por objetivo melhorar a capacidade das organizações de atrair e reter profissionais com habilidades, comportamentos e competências, estimulando comportamentos alinhados com os requisitos dos processos individual e coletivo de aprendizado, de forma a adotar políticas de remuneração, associadas à aquisição de competências individuais, ao desempenho da equipe e da organização. As organizações devem focar o desenvolvimento com base nas pessoas. Deve haver uma busca pela diversidade, o planejamento da carreira e o estímulo ao aprendizado (TERRA, 2001).

Dimensão 5 - Sistemas de informação. Nessa dimensão abordam-se os processos de geração, difusão e armazenamento de conhecimento, dentro de um ambiente de confiança, transparência e colaboração. Terra (2001) aponta que o uso de tecnologias da Informação pode facilitar o processo de criação $e$ compartilhamento do conhecimento, porém, também é necessário o estímulo à comunicação eficiente em todos os níveis da organização com acesso às bases de conhecimento.

Dimensão 6 - Mensuração dos resultados. Essa dimensão tem por finalidade avaliar várias dimensões do capital intelectual. Para Terra (2001) é uma preocupação que a organização deve ter com relação a procedimentos para mensuração sob diversas perspectivas, financeira, operacional, estratégica e de divulgação.

Por fim, a Dimensão 7 - Aprendizado com o ambiente. Salienta-se nessa dimensão que 0 aprendizado acontece por intermédio de alianças com outras organizações e do estreitamento do relacionamento com clientes. O aprendizado com o ambiente é, segundo Terra (2001), a preocupação permanente da 
organização em aprender por meio do relacionamento com clientes, empresas, universidades e institutos de pesquisa.

Está implícito em cada uma destas dimensões o reconhecimento de que o capital humano, formado pelos valores e normas individuais e organizacionais, bem como, pelas competências, habilidades e atitudes de cada funcionário, é a mola propulsora da geração de conhecimento e valor nas organizações. Isto significa conhecer a necessidade de se promover valores apropriados à inovação e ao compartilhamento do conhecimento e estimular a motivação, o estabelecimento de contatos pessoais, a análise de diferentes perspectivas, a abertura para a efetiva comunicação e o desenvolvimento de habilidades pessoais e profissionais (FERREIRA; PILATTI, 2013).

Terra (1999) classificou a existência de três grupos de empresas (clusters): empresas que aprendem; empresas tradicionais e pequenas atrasadas.

No primeiro grupo estão as empresas que aprendem, ou seja, as que têm maior nível de envolvimento com as práticas de gestão do conhecimento (TERRA, 1999). Grupos que conseguem os melhores resultados no mercado. De acordo com Nonaka e Takeuchi (1997), as empresas criadoras de conhecimento são aquelas que criam, sistematicamente, novos conhecimentos, disseminam-nos pela organização inteira e, rapidamente, os incorporam a novas tecnologias e produtos.

O segundo grupo, das empresas tradicionais, é composto por empresas que não têm tanto envolvimento com a gestão do conhecimento. Não alcançam resultados tão expressivos, garantem uma penetração no mercado externo bem menor e tem poucas chances de atrair capital estrangeiro (TERRA, 1999).

Já no terceiro grupo, das pequenas atrasadas, é composto por empresas que praticamente desprezam as práticas de gestão do conhecimento. São de capital predominantemente nacional, têm menor ganho recente de market share e estão, quase sempre, em terceiro lugar (ou menos ainda) em termos de posição de mercado. Não conseguem evoluir. Normalmente, não realizam qualquer atividade visando o mercado internacional (TERRA, 1999).

\section{METODOLOGIA}

O presente estudo caracteriza-se como exploratório, de natureza aplicada e abordagem quali-quantitativa, desenvolvido em uma indústria do setor metalmecânico. 
A amostra caracterizou-se por três gestores, pelo gerente de produção, pelo responsável pelo $\mathrm{RH}$ e por sessenta e nove colaboradores da produção, totalizando setenta e quatro respondentes.

O instrumento de pesquisa foi um questionário com 41 questões sobre as 7 dimensões da gestão do conhecimento, seguindo o modelo proposto por Terra (2001), o qual avalia a existência de ações que sejam compatíveis com a implantação de um processo de gestão do conhecimento. Foi utilizada uma escala do tipo Likert, composta por 5 pontos. Cada questão pode ser assim avaliada: (5) concordo totalmente, (4) concordo, (3) concordo parcialmente, (2) discordo e (1) discordo totalmente.

Foram criadas categorias, seguindo as sete dimensões propostas por Terra (2001). Cada dimensão teve os resultados organizados em tabelas, nas quais estão contidas as respostas emitidas pelos pesquisados, a média geral e a média aritmética simples obtida por assertiva.

$\mathrm{Na}$ tabulação dos dados foi registrado o escore indicado pelo respondente para cada questão, em seguida realizado o cálculo do grau de concordância representativo de cada escore utilizando a fórmula:

Grau $=(a \times 5)+(b \times 4)+(c \times 3)+(d \times 2)+(e \times 1) / n$

Onde: a, b, c, d, e representam o número de respostas dadas em cada grau.

Onde: $\mathrm{n}$ representa o número total de respostas.

Os resultados, baseados em classificação proposta por Terra (1999), foram classificados de acordo com seu grau de concordância, observando os seguintes intervalos:
a) Média igual ou superior a 3,5 (alto grau de concordância);
b) Média entre 3,1 e 3,4 (médio grau de concordância);
c) Média entre 2,6 e 3,0 (baixo grau de concordância);
d) Média igual ou inferior a 2,5 (baixíssimo grau de concordância). 


\section{RESULTADOS E DISCUSSÃO}

Nas tabelas seguintes são apresentadas as sete dimensões da gestão do conhecimento com o grau de concordância ou discordância para cada prática de gestão registrada na organização.

$\mathrm{Na}$ tabela 1, apresentam-se os resultados obtidos para a dimensão 1 Fatores estratégicos e o papel da alta administração.

Tabela 1: Fatores estratégicos e o papel da alta administração

\begin{tabular}{c|c|c}
\hline Item & Indicador & Grau \\
\hline 1.1 & $\begin{array}{c}\text { Existe elevado nível de consenso sobre quais são as core } \\
\text { competences da empresa, ou seja, quais são os pontos } \\
\text { fortes da empresa em termos de habilidades e } \\
\text { competências. }\end{array}$ & 4,6 \\
\hline 1.2 & $\begin{array}{c}\text { A macroestratégia da empresa é comunicada, amplamente, } \\
\text { para todos os níveis organizacionais. }\end{array}$ & 3,9 \\
\hline 1.3 & $\begin{array}{c}\text { A alta administração estabelece, frequentemente, metas } \\
\text { desafiadoras e um sentido de urgência para a mudança da } \\
\text { realidade em direção a uma visão estabelecida. }\end{array}$ & 4,5 \\
\hline
\end{tabular}

Fonte: Terra (2001).

Pode-se identificar, analisando a organização, que a estratégia dos gestores está voltada à criação do conhecimento, realizada por meio do compartilhamento do mesmo nas rotinas de trabalho e nos treinamentos, bem como nas conversas informais nos ambientes da empresa. O papel da alta administração está alinhado à criação do conhecimento, na definição clara da missão, visão, dos valores e dos objetivos.

É papel da gerência criar a necessidade de inovação na organização, de clarificação da estratégia e definição de metas. A alta administração também tem papel indispensável na definição dos campos do conhecimento, possibilitando que os colaboradores focalizem os esforços e estejam engajados no aprendizado contínuo (SVEIBY, 1998).

A gestão do conhecimento está intrinsecamente ligada à capacidade das empresas em utilizarem e combinarem as várias fontes e tipos de conhecimento organizacional para desenvolverem competências específicas e capacidade 
inovadora, que se traduzem, permanentemente, em novos produtos, processos, sistemas gerenciais e liderança de mercado (GOODRICH, 2007).

Na tabela 2, apresentam-se os resultados obtidos para a dimensão 2 - Cultura e valores organizacionais.

Tabela 2: Cultura e valores organizacionais

\begin{tabular}{|c|c|c|}
\hline Item & Indicador & Grau \\
\hline 2.1 & $\begin{array}{l}\text { A missão e os valores da empresa são promovidos, de } \\
\text { forma consistente, por atos simbólicos e ações. }\end{array}$ & 4,1 \\
\hline 2.2 & $\begin{array}{c}\text { Há um elevado sentimento de confiança entre empresa e } \\
\text { funcionários; existe, de maneira geral, um grande orgulho } \\
\text { em trabalhar para a empresa. }\end{array}$ & 3,9 \\
\hline 2.3 & As pessoas não estão focadas apenas no curto prazo. & 4,5 \\
\hline 2.4 & $\begin{array}{l}\begin{array}{l}\text { Estimula-se a experimentação. Há liberdade para tentar e } \\
\text { falhar. }\end{array}\end{array}$ & 4,2 \\
\hline 2.5 & $\begin{array}{l}\text { Existe uma grande honestidade intelectual na empresa, } \\
\text { ou seja, as pessoas são autênticas e deixam evidente } \\
\text { aquilo que conhecem e também o que não conhecem. }\end{array}$ & 4,1 \\
\hline 2.6 & $\begin{array}{c}\text { As pessoas estão preocupadas com toda a organização e } \\
\text { não apenas com sua área de trabalho, ou seja, buscam } \\
\text { uma otimização conjunta. }\end{array}$ & 4,1 \\
\hline 2.7 & $\begin{array}{c}\text { Reconhece-se que tempo é um recurso importante para o } \\
\text { processo de inovação. }\end{array}$ & 4,6 \\
\hline 2.8 & $\begin{array}{l}\text { Novas ideias são valorizadas. Há permissão para discutir } \\
\text { ideias "bobas". }\end{array}$ & 3,5 \\
\hline 2.9 & As realizações importantes são comemoradas. & 3,5 \\
\hline 2.10 & Há grande tolerância para piadas e humor. & 4,6 \\
\hline 2.11 & $\begin{array}{l}\text { Realizam-se, com frequência, reuniões informais, fora do } \\
\text { local de trabalho, para a realização de brainstormings. }\end{array}$ & 3,7 \\
\hline 2.12 & $\begin{array}{l}\text { Os layouts são conducentes à troca informal de } \\
\text { informação (uso de espaços abertos e salas de reunião). } \\
\text { São poucos os símbolos de status e hierárquicos. }\end{array}$ & 3,8 \\
\hline
\end{tabular}

Fonte: Terra (2001).

$\mathrm{Na}$ dimensão dois, visualiza-se que a organização tem a cultura propícia à criação e ao compartilhamento, principalmente pelo fato de que a organização trabalha com uma metodologia colaborativa, na qual todos cooperam e ocorre o compartilhamento e a criação do conhecimento. É possível visualizar o direcionamento da organização. No estudo de caso também percebe-se que a cultura é utilizada para compartilhar conhecimento e informação junto aos colaboradores, de forma que promove a inovação, a experimentação e o aprendizado dos participantes. A organização tem claramente definida sua visão, missão e valores os quais são difundidos, divulgados e praticados por todos. 
É importante que o aprendizado, a colaboração e o compartilhamento sejam considerados parte do dia-a-dia dos colaboradores e as estratégias e objetivos estratégicos foquem a criação do conhecimento organizacional. Ou seja, o ambiente organizacional deve ser propício ao compartilhamento. Algumas características são: os colaboradores se sentirem estimulados pelas suas atividades, conversas entre colaboradores de mesmo e de diferentes níveis hierárquicos, relações informais, tempo hábil para o aprendizado, foco no longo prazo e não apenas na área de trabalho de cada um, abertura, colaboração e flexibilidade para trocar experiências de sucesso e erros, divulgação de resultados, e, discussão de valores da organização como algo relevante (LIN, 2007).

$\mathrm{Na}$ tabela 3 , apresentam-se os resultados obtidos para a dimensão 3 Estrutura organizacional.

Tabela 3: Estrutura organizacional

\begin{tabular}{c|c|c}
\hline Item & Indicador & Grau \\
\hline 3.1 & $\begin{array}{c}\text { Há um uso constante de equipes multidisciplinares e } \\
\text { formais que se sobrepõem à estrutura formal tradicional e } \\
\text { hierárquica. }\end{array}$ & 4,4 \\
\hline 3.2 & $\begin{array}{c}\text { Há um uso constante de equipes adhoc ou temporárias, } \\
\text { com grande autonomia totalmente dedicadas a projetos } \\
\text { inovadores. }\end{array}$ & 3,9 \\
\hline 3.3 & $\begin{array}{c}\text { Pequenas reorganizações ocorrem com frequência, de } \\
\text { forma natural, para se adaptar às demandas do ambiente } \\
\text { competitivo. }\end{array}$ & 4,2 \\
\hline 3.4 & $\begin{array}{c}\text { As decisões são tomadas no nível mais baixo possível. O } \\
\text { processo decisório é ágil; a burocracia é mínima. }\end{array}$ & 4,3 \\
\hline
\end{tabular}

Fonte: Terra (2001).

Com relação à terceira dimensão verificou-se que na organização existe uma estrutura hierárquica bem definida, entretanto, os colaboradores são ativos nos processos. As decisões são tomadas com burocracia, porém, cada decisão é debatida com os participantes dos processos, o que torna os mesmos ágeis e precisos, pois vão de encontro com as reais necessidades organizacionais.

Ipe (2003) ressalta que as organizações devem apresentar modelos de estruturas flexíveis que favorecem a inovação e o aprendizado, estimulando o trabalho em equipes. Algumas novas estruturas estão sendo baseadas na multidisciplinaridade e alto grau de autonomia.

$\mathrm{Na}$ tabela 4, apresentam-se os resultados obtidos para a dimensão 4 Administração de recursos humanos. 
Tabela 4: Administração de recursos humanos.

\begin{tabular}{|c|c|c|}
\hline Item & Indicador & Grau \\
\hline 4.1 & O processo de seleção é bastante rigoroso. & 4,5 \\
\hline 4.2 & $\begin{array}{l}\text { Há uma busca de diversidade (personalidades, } \\
\text { experiências, culturas, educação formal, etc.) e aumento da } \\
\text { criatividade por meio do recrutamento. }\end{array}$ & 3,9 \\
\hline 4.3 & $\begin{array}{l}\text { O planejamento de carreira busca dotar os funcionários de } \\
\text { diferentes perspectivas e experiências. }\end{array}$ & 3,5 \\
\hline 4.4 & $\begin{array}{c}\text { O escopo das responsabilidades dos cargos é, em geral, } \\
\text { bastante abrangente. }\end{array}$ & 4,6 \\
\hline 4.5 & $\begin{array}{c}\text { Há um elevado investimento e incentivo ao treinamento e } \\
\text { desenvolvimento profissional e pessoal dos funcionários. } \\
\text { Estimulam-se treinamentos que levam ao } \\
\text { autoconhecimento. }\end{array}$ & 4,6 \\
\hline 4.6 & $\begin{array}{c}\text { Estimula-se o aprendizado pela ampliação dos contatos e } \\
\text { interações com outras pessoas de dentro e fora da } \\
\text { empresa. }\end{array}$ & 3,9 \\
\hline 4.7 & $\begin{array}{l}\text { O treinamento está associado às necessidades da área } \\
\text { imediata de trabalho do funcionário e/ou às necessidades } \\
\text { estratégicas da empresa. }\end{array}$ & 4,4 \\
\hline 4.8 & $\begin{array}{c}\text { Há um baixo turnover (número de pessoas que se demitem } \\
\text { ou são demitidos) na empresa em comparação a outras } \\
\text { empresas do mesmo setor }\end{array}$ & 4,5 \\
\hline 4.9 & $\begin{array}{l}\text { A evolução dos salários está associada, principalmente, à } \\
\text { aquisição de competências e não ao cargo ocupado. }\end{array}$ & 3,1 \\
\hline 4.10 & $\begin{array}{l}\text { Existem esquemas de premiação e reconhecimento por } \\
\text { resultados e contribuições extraordinárias. }\end{array}$ & 3,1 \\
\hline 4.11 & $\begin{array}{l}\text { Existem esquemas de pagamentos associados ao } \\
\text { desempenho da equipe (e não apenas ao desempenho } \\
\text { individual). Os créditos são compartilhados. }\end{array}$ & 3,1 \\
\hline 4.12 & $\begin{array}{l}\text { Existem esquemas de participação nos lucros envolvendo } \\
\text { a maior parte dos funcionários. }\end{array}$ & 3,3 \\
\hline 4.13 & $\begin{array}{l}\text { Existem esquemas de participação societária envolvendo a } \\
\text { maior parte dos funcionários. }\end{array}$ & 3,2 \\
\hline
\end{tabular}

Fonte: Terra (2001).

Identifica-se que a organização analisada procura fazer uma seleção dos recursos humanos levando em consideração a diversidade. O resultado demonstra que o processo de seleção é rigoroso, atingindo grau de concordância de 4,5. A organização também procura promover a constante capacitação da equipe, por meio de programas de capacitação, com bastante frequência. Essas atitudes tornam facilitadas as fases de geração, difusão, armazenamento e compartilhamento do conhecimento individual para o coletivo. Quanto aos esquemas de premiação e reconhecimento por resultados, esquemas de pagamentos associados ao desempenho da equipe, participação dos lucros e esquemas de participação societária, a percepção dos gestores evidenciou necessidade de a organização 
reavaliar sua política de reajustes salariais, desenvolver estudos visando à implantação de programas de participação nos lucros ou porcentagem maior para seus vendedores, além de programas de participação societária, reconhecimento e premiação por resultados atingidos, uma vez que estas práticas contribuem para a motivação, aumentando o grau de envolvimento e comprometimento de seus colaboradores.

Os autores Bartol e Srivastava (2002) apresentam algumas características que se destacam para prática de recursos humanos associadas à criação de conhecimento: atrair e manter pessoas com habilidades, comportamentos e competências que adicionem e incrementem os fluxos de conhecimento, estimular comportamentos de aprendizado e fortalecimento de core competencies, como realizações de planos de carreira e treinamentos, estabelecer esquemas de remuneração que estejam associados à aquisição de competências individuais, da equipe e da empresa, pois o que mantém as pessoas unidas são seus interesses comuns tanto de aprendizado como de desenvolvimento pessoal, criar um grau de identificação dos colaboradores com a organização, expresso por um sentimento de orgulho, estimulando a inovação, aumentando a confiança e criando um ambiente mais cooperativo e propício ao compartilhamento e criação de conhecimento, pois, são necessários para isto muito contato humano, intuição, conhecimento tácito, cooperação e explicitação.

$\mathrm{Na}$ tabela 5, apresentam-se os resultados obtidos para a dimensão 5 Sistemas de Informação.

Tabela 5: Sistemas de informação

\begin{tabular}{c|c|c}
\hline Item & Atividade & Grau \\
\hline 5.1 & $\begin{array}{c}\text { A comunicação é eficiente em todos os sentidos (de cima para } \\
\text { baixo, de baixo para cima e entre áreas distintas). }\end{array}$ & 4,5 \\
\hline 5.2 & $\begin{array}{c}\text { As informações são compartilhadas. Existe amplo acesso, por } \\
\text { parte de todos os funcionários, à base de dados e conhecimento } \\
\text { da organização. }\end{array}$ & 4,6 \\
\hline 5.3 & $\begin{array}{c}\text { Há grande disciplina, eficiência e incentivo para a documentação } \\
\text { do conhecimento e Konw-how existente na empresa. }\end{array}$ & 4,7 \\
\hline
\end{tabular}

Fonte: Terra (2001).

Neste sentido, verifica-se que a organização analisada utiliza diversas tecnologias de informação e comunicação para facilitar a troca entre os colaboradores e até mesmo com o público externo, por meio do site institucional, de matérias publicadas em revistas do ramo de atuação e por meio da participação em 
projetos de nível nacional que estimulam o comprometimento da empresa. A empresa já participou de vários processos de premiação na área de atuação e conquistou certificação nacional. Também é possível salientar que os sistemas de informação são visíveis na construção de máquinas e equipamentos nos processos de fabricação.

Sveiby (1998) apresenta a tecnologia da informação como elemento facilitador ao processo de compartilhamento do conhecimento, entretanto, apesar dos grandes avanços para auxílio aos processos de geração, difusão e armazenamento de informações e de conhecimento, os papéis das relações pessoais e de conhecimento tácito para gerar aprendizado organizacional e as relações de um ambiente propício ao compartilhamento devem acontecer com confiança, transparência e colaboração dos indivíduos da organização.

$\mathrm{Na}$ tabela 6, apresentam-se os resultados obtidos para a dimensão 6 Mensuração de resultados.

Tabela 6: Mensuração de resultados

\begin{tabular}{c|c|c}
\hline Item & Atividade & Grau \\
\hline 6.1 & $\begin{array}{c}\text { Existe uma grande preocupação em medir resultados sob } \\
\text { várias perspectivas (financeiras, operacionais, estratégicas, } \\
\text { aquisição do conhecimento). }\end{array}$ & 4,4 \\
\hline 6.2 & Os resultados são amplamente divulgados internamente. & 4,8 \\
\hline
\end{tabular}

Fonte: Terra (2001).

$\mathrm{Na}$ empresa pesquisada, a mensuração dos resultados é realizada mediante ferramentas de controle nos processos. Os resultados são divulgados no contexto organizacional de forma a possibilitar a tomada de decisão e melhorias organizacionais.

A mensuração de resultados é, de acordo com Terra (2001), uma preocupação que a organização deve ter com relação a procedimentos para mensuração sob diversas perspectivas, financeira, operacional, estratégica e de divulgação, aponta a necessidade de obter novas maneiras de avaliação do capital intelectual.

$\mathrm{Na}$ tabela 7, apresentam-se os resultados obtidos para a dimensão 7 Aprendizado com o ambiente. 
Tabela 7: Aprendizado com o ambiente

\begin{tabular}{c|c|c}
\hline Item & Atividade & Grau \\
\hline 7.1 & $\begin{array}{c}\text { A empresa aprende muito com seus clientes. Existem } \\
\text { vários mecanismos formais e informais bem estabelecidos } \\
\text { para essa finalidade. }\end{array}$ & 3,8 \\
\hline 7.2 & $\begin{array}{c}\text { A empresa tem habilidade na gestão de parcerias com } \\
\text { outras empresas. }\end{array}$ & 4,5 \\
\hline 7.3 & $\begin{array}{c}\text { A empresa tem habilidade na gestão de parcerias com } \\
\text { universidades e institutos de pesquisa (contratação de } \\
\text { pesquisa externa). }\end{array}$ & 4,1 \\
\hline 7.4 & $\begin{array}{c}\text { A decisão de realizar alianças está, frequentemente, } \\
\text { relacionada a decisões estratégicas e de aprendizado } \\
\text { importantes. Os funcionários da empresa percebem, muito } \\
\text { claramente, esse objetivo de aprendizado. }\end{array}$ & 4,8 \\
\hline
\end{tabular}

Fonte: Terra (2001).

Verifica-se que a organização constantemente promove parcerias com várias instituições sejam privadas, públicas, de ensino e pesquisa ou institutos. Frequentemente promove treinamentos para os colaboradores tendo como parceria o Senai, o Sebrae e instituições de ensino. Os objetivos e visão da organização são claros, existe um incentivo ao compartilhamento, baseia-se em estratégias voltadas à criação tendo a alta administração como facilitadora ao processo de criação e compartilhamento.

O aprendizado com o ambiente é, segundo Terra (2001), a preocupação permanente da organização em aprender por meio do relacionamento com clientes, empresas, universidades e institutos de pesquisa. $O$ autor enfatiza que ó aprendizado com o ambiente ocorre pela necessidade do engajamento da organização nos processos de aprendizado.

\section{CONCLUSÃO}

Pelos resultados da pesquisa empírica e comparando-o ao embasamento teórico foi possível concluir que a organização está alinhada às sete dimensões da Gestão do Conhecimento, propostas por Terra (2001) e, portanto, cria condições propícias ao compartilhamento e à criação de conhecimento. A presente pesquisa considerou que na evolução dos modelos de gestão, o conhecimento tornou-se recurso estratégico e as organizações que souberem criar e compartilhar os conhecimentos gerados internamente irão se sobressair frente às demais. 
Conclui-se com esse estudo que a alta administração é vista como facilitadora; que a cultura organizacional propicia o compartilhamento pela utilização de uma metodologia com estímulo à socialização, experimentação e valorização das ideias; que apesar da estrutura hierárquica, há incentivo à participação, com equipes multidisciplinares que detém certa autonomia; que há um processo de seleção voltado a especialidades e qualificações diversas, com constantes capacitações de seus colaboradores; que a organização utiliza diversas tecnologias para facilitar a troca de informações e conhecimentos e busca treinar os colaboradores para uso destas tecnologias; que não existem métricas definidas para avaliação dos resultados do projeto e, finalmente, que o aprendizado com o ambiente se dá por meio de parcerias, treinamentos e da própria diversidade cultural.

\section{REFERÊNCIAS}

BARTOL, K. M.; SRIVASTAVA, A. Encouraging knowledge sharing: The role of organizational reward systems. Journal of Leadership \& Organizational Studies, v. 9, n. 1,p.64-77, 2002.

DAVENPORT, T. Reengenharia de processos. Rio de Janeiro: Campus, 1994.

FERREIRA, C. L.; PILATTI, L. A. Analysis of the Seven Dimensions of Knowledge Management in Organizations. Journal of Technology Management \& Innovation, [S.I.], v. 8, p. 53-63, apr. 2013. Disponível em:

<http://www.jotmi.org/index.php/GT/article/view/1163>. Acesso em: 30 Sep. 2013.

GARVIN, D. A. Leveraging processes for strategic advantage. Harvard Business Review, v. 73, n. 5, p. 76-90, sep./oct. 1995.

GOODRICH, N.; AIMAN-SMITH, L. What does your most important customer want? Research Technology Management, v. 50, n. 2, p. 26-35, 2007.

IPE, M. Knowledge sharing in organizations: a conceptual framework. Human Resource Development Review, v. 2, n. 4, p. 337-359, dec. 2003.

LEHTIMAKI, A. Management of the innovation process in small companies in Finland. IEEE - Transactions on Engineering Management, v. 38, n. 2, p. 120-126, may 1991.

LIN, G. Effects of extrinsic and intrinsic motivation on emplouee knowledge sharing intentions. Journal of Information Science, v. 33, n. 2, p. 135-149, 2007.

NONAKA, I.; TAKEUCHI, H. Criação de conhecimento na empresa: como as empresas japonesas geram a dinâmica da inovação. 13. ed., Rio de Janeiro: Elsevier, 1997. 
OSTROFF, F.; SMITH, D. The horizontal organization. The McKinsey Quarterly, n.1, p. 148-168, 1992.

PILATTI, L. A.; BEJARANO, V. C. Qualidade de vida no trabalho: leitura e possibilidades no entorno. In: GONÇALVES, A.; GUTIERREZ, G. L.; VILARTA, R. (orgs). Gestão da qualidade de vida na empresa. Campinas: IPES, 2005.

SVEIBY, K. E. A nova riqueza das organizações: gerenciando e avaliando patrimônios de conhecimento. Rio de Janeiro: Campus, 1998.

TERRA, J. C.C. Gestão do Conhecimento: Aspectos Conceituais e Estudo Exploratório Sobre as Práticas de Empresas Brasileiras. 1999. 311f. Tese (Doutorado em Engenharia de Produção) - Escola Politécnica da USP.

TERRA, J. C.C. Gestão do Conhecimento: o grande desafio empresarial. 3. ed. São Paulo: Negócio Editora, 2001. 